\title{
O uso do calendário socioecológico na estruturação do currículo das escolas indígenas: uma proposta interdisciplinar e intercultural
}

The use of the socioecológico calendar in structuring the curriculum of indigenous schools: an interdisciplinary and intercultural proposal

El uso del calendario socioecológico en la estructuración del currículo de las escuelas indígenas: una propuesta interdisciplinar e intercultural

Cleunice de Barros Nunes ${ }^{1}$

Juarez Melgaço Valadares²

Célio da Silveira Júnior ${ }^{2}$

DOI: http://dx.doi.org/10.20435/serie-estudos.v22i45.997

\begin{abstract}
Resumo: Neste trabalho, analisamos a trajetória de um grupo de professores indígenas da etnia Xakriabá, que vivem no Norte de Minas Gerais, e que, nos últimos anos, tem se voltado para a incorporação e valorização da sua cultura no currículo de suas escolas. Como instrumento teórico-metodológico, esses professores têm se amparado no Calendário Socioecológico proposto por Gasché. A partir das entrevistas realizadas com dois professores, buscamos os limites e as possibilidades que vivenciaram ao longo desse processo: Que conteúdos construíram para o currículo, a partir do uso do calendário socioecológico? Que dificuldades encontraram? Por meio de uma abordagem qualitativa, procuramos apreender a dinâmica, a complexidade e o desenrolar da trama curricular na escola, a partir dos significados atribuídos por seus atores ao cumprimento da tarefa. Apoiados no referencial do francês René Kaës, buscamos os impasses vividos e as saídas encontradas pelos professores, de forma a aprofundar nosso conhecimento sobre a função social da escola para os povos indígenas. As respostas obtidas nos evidenciaram as dificuldades de se incorporar a "cultura indígena" em articulação com os saberes acadêmicos. Conclusões importantes sobre os desafios na implementação de experiências curriculares inovadoras são mencionadas, bem como são indicados alguns impactos para a formação docente.
\end{abstract}

Palavras-chave: currículo escolar; interculturalidade; calendário socioecológico.

\footnotetext{
${ }^{1}$ Escola Estadual Indígena Kuhinãn, Aldeia Rancharia, Território Indígena Xakriabá, Minas Gerais, Brasil.

2 Universidade Federal de Minas Gerais (UFMG), Belo Horizonte, Minas Gerais, Brasil.
} 


\begin{abstract}
In this paper we analyze the path of a group of indigenous teachers Xakriabá ethnicity, living in the North of Minas Gerais. In recent years, they have focused on the development and appreciation of their culture in the curriculum of their schools. As a methodological tool, these teachers have used the socioecological Calendar. Through a qualitative approach, we conducted interviews with two teachers, we seek the limits and possibilities experienced throughout this process: What content built into the curriculum, from the use of socio-ecological calendar? What difficulties encountered? We seek to grasp the dynamics, complexity and the development of curriculum development at the school, from the meanings assigned by their actors to fulfill the task. Supported on psychoanalysis French René Kaës, we seek the lived impasses and outputs by the teachers, in order to deepen our knowledge of the school's social role for indigenous peoples. The analysis showed the difficulties of incorporating the "indigenous culture" in conjunction with academic knowledge. Conclusions on the challenges in implementing innovative curricular experiences are mentioned and are given some impact on teacher training.
\end{abstract}

Key words: school curriculum; border cultures; socioecological calendar.

Resumen: En este trabajo se analiza la trayectoria de un grupo de maestros indígenas Xakriabá etnia, que viven en el norte de Minas Gerais. En los últimos años, se han centrado en el desarrollo y la valoración de su cultura en el plan de estudios de sus escuelas. Como herramienta metodológica, estos profesores han utilizado el Calendario socioecológica Gasché. A través de un enfoque cualitativo, se realizaron entrevistas con dos maestros, buscamos los límites y posibilidades experimentado a lo largo de este proceso: ¿Qué contenido incorporado en el plan de estudios, a partir de la utilización de calendario socio-ecológica? ¿Qué dificultades encontradas? Buscamos captar la dinámica, la complejidad y el desarrollo de desarrollo curricular en la escuela, a partir de los significados asignados por sus actores para cumplir la tarea. Apoyado en el psicoanálisis francés René Kaës, buscamos los puntos muertos duración y salidas de los profesores, con el fin de profundizar en el conocimiento de la función social de la escuela para los pueblos indígenas. El análisis mostró las dificultades de incorporar la "cultura indígena", en relación con el conocimiento académico. Conclusiones sobre los desafíos en la implementación de experiencias curriculares innovadoras se mencionan y se les da un cierto impacto en la formación de profesores.

Palabras clave: plan de estudios; culturas fronterizas; calendario socioecológico.

\title{
1 INTRODUÇÃO
}

A legislação em vigor reconhece, em seu texto, a importância de se construir uma escola indígena diferenciada, cujo currículo respeite as suas tradições e seus saberes. Implica, sobretudo, perceber a escola como local onde a cultura universal e os saberes tradicionais se encontram, propiciando relações de poder, de conflitos, e impactos sobre as identidades envolvidas. Tal aspecto sugere que pensar um currículo intercultural se associa à articulação entre o comum e a parte flexível, não como relação excludente ou folclore, mas como contato cultural:

A aposta do contato cultural na educação ajuda a compreender que esta tensão conceitual é constitutiva. Logo, articular o nacional e o local expressa a capacidade de o currículo potencializar a síntese cultural de cada povo. É, 
O uso do calendário socioecológico na estruturação do currículo das escolas indígenas:

uma proposta interdisciplinar e intercultural

ainda, oferecer aos educandos a possibilidade de viver em contato cultural e enriquecer-se através dele. (GUTIERREZ, 2014, p. 77).

Ao longo dos séculos, a concepção de uma cultura hegemônica fez com que a cultura indígena se estereotipasse na sociedade. Por sua vez, a concepção positivista da ciência, presente em nossas escolas, contribuiu para diluir as demais formas de representação do mundo, dentre elas a cultura indígena. Essa modalidade positivada (D’ANGELIS, 2006) gestou dualidades reconhecidas para os povos indígenas (atrasado $x$ desenvolvido, preguiçosos $x$ trabalhador, primitivo $x$ civilizado), projetando sobre estes uma visão romântica do índio: forte, pelado, próximo à natureza, emplumado e afastado das tecnologias. Tais dualidades mostram um ocultamento da cultura indígena frente aos saberes considerados hegemônicos.

Na década de 1980, o desprezo pela cultura popular e saberes tradicionais, e a defesa da superioridade do conhecimento científico, começaram a ser questionados por educadores e professores da área de Ciências (EL-HANI; SEPÙLVEDA, 2006). Por sua vez, os povos indígenas retornam defendendo não apenas o direito à escolarização básica, mas a luta contra o universalismo anônimo que ameaça de exclusão as diferenças nas escolas e na sociedade. Essas ações implicam construir uma educação intercultural, onde a cultura indígena se faça presente. 0 artigo $3^{\circ}$ do Decreto 6.861, de 2009, menciona que as escolas indígenas terão diretrizes curriculares específicas voltadas ao ensino intercultural e bilíngue, respeitadas as atividades sociais, culturais, religiosas e econômicas de cada povo. No artigo $2^{\circ}$, observamos os seus objetivos:

Art. $2^{\circ}$ - São objetivos da educação escolar indígena:

I- valorização das culturas dos povos indígenas e a afirmação e manutenção de sua diversidade étnica;

II- fortalecimento das práticas socioculturais e da língua materna de cada comunidade indígena;

III- formulação e manutenção de programas de formação de pessoal especializado, destinados à educação escolar nas comunidades indígenas;

IV- desenvolvimento de currículos e programas específicos, neles incluindo os conteúdos culturais correspondentes às respectivas comunidades;

$\checkmark$ - elaboração e publicação sistemática de material didático específico e diferenciado; e

VI- afirmação das identidades étnicas e consideração dos projetos societários definidos de forma autônoma por cada povo indígena.

Em um artigo provocador, Wilmar D'Angelis (2006) sugere que a cultura indígena não necessita de escola para sua transmissão. Para Manuela Carneiro da 
Cunha (2014), valorizar a cultura indígena na escola é uma coisa, mas ensiná-la dentro da escola é um paradoxo; a cultura indígena não é feita de conteúdos, mas de procedimentos, de mecanismos de transmissão, rituais e poderia transformar-se em apenas informações nas escolas. Encontramos tensões e impasses entre os propósitos dos povos indígenas e as intenções dos professores das universidades e dos gestores das secretarias de educação no que se referem à construção de uma escola diferenciada. As formas de apropriação da escola pelos povos indígenas são diversas, e entender o que eles valorizam nessas experiências é o que permitirá uma análise mais crítica.

Em visitas às escolas das aldeias do Povo Xakriabá (Minas Gerais), notamos que a alternativa destinada a lidar com a produção do conhecimento escolar, simultaneamente às articulações entre os saberes científicos e os conhecimentos tradicionais, tem ocorrido a partir do Calendário Socioecológico proposto por Gasché (2010). A novidade está no questionamento à seleção cultural oferecida pelo sistema educativo tradicional, de maneira que os planejamentos que se assentam sobre a cultura local começam a perpassar o espaço e a discussão sobre a construção dos currículos. Sobretudo, o Calendário é um instrumento teórico-metodológico com o objetivo de desenvolver uma educação intercultural crítica, que parte dos saberes indígenas tradicionais para articular-se com os saberes científicos. Nesse caso, a interseção entre os saberes não deixa intacto o currículo hegemônico, uma vez que o currículo comum é construído sobre outras bases.

Neste texto, analisamos o currículo que vem sendo construído na Escola Estadual Indígena Kuhinãn, na Aldeia Rancharia, povo indígena Xakriabá. A preocupação dos professores tem como eixo a construção de uma escola indígena com o currículo capaz de incorporar a cultura local. Os povos Xakriabá, em número próximo de dez mil indígenas, vivem no Norte do Estado de Minas Gerais. O texto é de autoria de uma professora indígena que atua na escola, em conjunto com seus orientadores que atuam no FIEI/FaE/UFMG. Os dados deste trabalho foram coletados pela professora para seu trabalho de conclusão do Curso de Licenciatura de Formação Intercultural para Educadores Indígenas (FIEI), área de Ciências da Vida e da Natureza (CVN), da Faculdade de Educação da Universidade Federal de Minas Gerais (UFMG). Acreditamos que se constitui numa experiência original, uma vez que os dados se referem às tensões que apareceram na articulação entre os conhecimentos acadêmicos e os saberes tradicionais do povo Xakriabá presentes no currículo. Perguntamos: Como essa cultura aparece nos currículos escolares? 
Compreender esses aspectos implica aprofundar nosso conhecimento sobre a função social da escola para os povos indígenas em suas articulações com a cultura local, levando em consideração tanto a construção do currículo da educação básica em suas aldeias quanto os processos de formação docente existentes nos diversos cursos nas universidades federais (GOMES; MIRANDA, 2014). Assim, as perguntas feitas pelos educadores indígenas em suas escolas, bem como as tensões que vivem, tendem a aumentar a complexidade da formação acadêmica nos cursos de formação intercultural para educadores indígenas. Nestes, pensamos nas articulações e fronteiras entre o conhecimento acadêmico e os saberes tradicionais indígenas. Indagamos: Como ensinar os conceitos científicos e simultaneamente manter um respeito e tolerância pelo saber e cultura do alunado?

\section{CALENDÁRIO SOCIOECOLÓGICO}

O Calendário relaciona-se com as atividades que ocorrem em cada aldeia indígena ao longo de um ano. As atividades são listadas mensalmente, podendo sofrer variações entre povos e aldeias. O calendário do Povo Xakriabá é marcado por dois tempos: o tempo da seca, de abril a setembro, e o tempo das águas, de outubro a março. No interior dessa marcação, há uma diversidade de atividades: produtivas, movimentos sociais, ritos, festas, dentre outras. Dessa forma, o calendário é construído em cada escola, em cada aldeia; o ponto de partida, conforme mencionamos, são as atividades e os conhecimentos tradicionais presentes. A partir delas, é escolhida uma temática que servirá de "eixo gerador de tema", sob o qual todos os conteúdos, independentemente do nível escolar, serão estudados. Após explicitar e sistematizar os conhecimentos indígenas implícitos nas atividades, eles são articulados aos saberes das disciplinas. Alguns passos foram elaborados como forma de montar o Calendário e, simultaneamente, pensar as atividades a serem trabalhadas na escola: reconhecer o saber fazer presente na atividade; identificar os tempos; identificar as atividades referentes àquele período; sistematizar as atividades e acoplar os seus eixos aos indicadores; fazer a ponte entre o conhecimento tradicional com o conhecimento escolar; identificar as fontes de pesquisa; produzir materiais educativos nas várias linguagens: escrita, oral, música, versos, com as crianças, jovens e velhos ${ }^{3}$.

\footnotetext{
${ }^{3}$ Vejamos um exemplo da construção dessas atividades, para o mês de maio, no povo Xakriabá. "Nesse mês, o caburé começa a cantar anunciando o frio que está chegando. As festas de Santa Cruz vão do dia 23 ou 24 de abril até o dia 02 ou 03 desse mês. As roças começam a serem roçadas, principalmente as que estão na mata, pois as folhas das árvores começam a cair". Atividades: Final das
} 
A elaboração do Calendário é feita a partir de alguns indicadores, que permitem um detalhamento maior na descrição das atividades: astronômicos (constelações, movimentos do sol e da lua, planetas, duração do dia, bichos, etc); climatológicos (vento, nuvens, estação do ano, etc); hidrológicas (enchente, vazante, movimento dos rios, nascentes, solo); biológicas (flora, fauna, presença e reprodução de animais, águas); ciclos das atividades (sociais, produtivas, artesanatos, rituais); atividades das crianças, jovens, velhos (o que cada um faz naquele período).

Em uma experiência vivida na Escola Estadual Indígena Kuhinãn, que fica na Aldeia Rancharia, Povo Xakriabá, escolheu-se como temática, para estruturação curricular da escola, em todos os seus níveis e modalidades, Da plantação da mandioca à produção da farinha. Primeiramente, professores e alunos realizaram diversas entrevistas com as pessoas da comunidade, a partir de um roteiro construído com antecedência. A seguir, eles acompanharam todas as fases das atividades, promovendo problematizações e discussões sobre o tema. Por fim, a partir de toda essa dinâmica, os docentes fizeram a sistematização dos conhecimentos, técnicas e saberes que a comunidade possuía. Todo esse movimento propiciou a formatação de uma lista de conhecimentos e atividades do currículo escolar.

No que se refere à Área CVN, as problematizações referiram-se às fases da lua para plantar e colher a mandioca, à distinção entre a mandioca boa e a brava, além de à prensa para retirar água da pasta de mandioca. De forma resumida, os conteúdos desenvolvidos foram: luz e sombra; movimento do sol, duração do dia; fases da lua; estações do ano; relógio de sol; localizações geográficas; da terra plana à terra esférica; momento de uma força; máquinas simples; máquinas hidráulicas e máquinas térmicas; mão de força; diversas máquinas presentes no cotidiano Xakriabá; plantio e adubação do solo; as queimadas; noções básicas de higiene; uso da água; mandioca brava e mandioca boa; energia e ambiente; produção de alimentos. Essa construção final contou com a participação de todos os docentes indígenas, além

festas de Santa Cruz; início do roçado; início da poeira, pele ressecada e doenças respiratórias; início de caída das folhas; colheita da feijoa e da abóbora; plantio de hortas. Indicadores: a) astronômicos: céu claro, estrelado, céu nublado com chuviscos, não se consegue ver as sete estrelas, céu avermelhado, dia menor do que a noite; b) Clima: sol frio, início da poeira e do frio, pele ressecada, doenças respiratórias, mês das mães, tempo de alegria; c) Vegetais: abóbora madura, milho seco, fava, andu, mandioca, hortas, maracujá, imbu; d) animais: canto do caburé, cutia e veado catingueiro; e) atividades dos membros da comunidade: ficam mais em casa, roçadas de capoeiras, corte de fava, plantar horta, produção de farinha, quebra do milho, participação nos festejos; f) Atividades das crianças: estudam, brincam, participam das atividades que acontecem em casa, na roça e dos festejos. 
O uso do calendário socioecológico na estruturação do currículo das escolas indígenas:

uma proposta interdisciplinar e intercultural

de professores e bolsistas da área CVN do FIEI/UFMG.

Nesse texto, discutiremos o uso do calendário na Escola Estadual Indígena Kuhinãn, como possibilidade de construir uma escola indígena diferenciada. Perguntase: Que saberes fizeram parte dessa construção curricular? Conseguiram realizar um trabalho de prazer e criação? Que significados nós encontramos nessas práticas?

Para tanto, realizamos duas entrevistas com professores indígenas que estão trabalhando com o calendário socioecológico na escola desde o seu início. Algumas conclusões importantes sobre formas de aproximação entre a cultura local, o território, a escola indígena e a formação docente no FIEI serão levantadas.

\section{REFERENCIAL TEÓRICO-CONCEITUAL}

Para analisar os dados, utilizaremos conceitos retirados do referencial do francês René Kaës (2005). Segundo o autor, os investimentos e contrainvestimentos na tarefa primária, - a formação -, são elementos da realidade comum, compartilhada e conflitiva, e fonte de prazer e sofrimento. Kaës, em seus trabalhos sobre os sujeitos, os grupos e as instituições, se pergunta: Como são vividos e elaborados os elementos presentes na ruptura da relação intra e intersubjetiva, no jogo das dependências dos grupos e da sociedade? O autor se volta sobre o que ocorre quando a experiência de ruptura questiona o sujeito na continuidade de si mesmo; na organização de suas identificações; no emprego de certos mecanismos de defesa; na coerência entre as suas formas de pensar e atuar; na confiança depositada nos grupos de pertencimento e na eficácia dos códigos comuns a todos que pertencem a esse conjunto. Em cada experiência deparamos com os valores negativos e hostis do estrangeiro: o não-eu, o não-vínculo, o não-nós e o não-o-mesmo.

Dessa forma, ele foca a sua análise exatamente nas zonas de fronteiriças ou momentos de ruptura, entre uma perda da segurança e no momento em que os novos laços ainda não estão construídos. Para compreender o que ocorre nessas situações, Kaës propõe o conceito de intermediário: um conector em um momento de ruptura, desencadeando tanto movimentos de criação, transformando o grupo, quanto situações de paralisia, bloqueando o grupo na consecução de seus objetivos. Exploramos, neste trabalho, dois intermediários: o contrato narcísico e o pacto denegativo. O primeiro se refere aos processos de identificação, aquilo que é comum aos dois lados separados, e que se constitui como uma ponte que permite a passagem em uma ruptura ou crise. O segundo conceito, o pacto denegativo, se refere àquilo que deverá ser recalcado de cada lado, ou por cada membro do conjunto, para que 
este se constitua; revela-se pelas hostilidades, incertezas e dúvidas demonstradas pelos membros do grupo nos momentos de crise. O conceito de intermediário é percebido nas relações entre continuidade e ruptura, permanência e transformação (KÄ̈S, 2005).

Buscamos, assim, suporte no referencial teórico para compreender os momentos de continuidade e ruptura nas práticas desenvolvidas na escola, e relatadas pelo professor durante a entrevista. Em quais momentos a ruptura dos elos provocou avanços ou a paralisia do grupo na construção de uma escola diferenciada?

\section{METODOLOGIA DE COLETA DOS DADOS}

Os dados foram coletados por meio de duas entrevistas individuais, gravadas em áudio e transcritas a posteriori. As entrevistas foram realizadas por uma professora indígena da própria escola, também envolvida no projeto pedagógico, e ambos os professores entrevistados formaram-se no FIEI/UFMG, e vêm trabalhando com o Calendário socioecológico como mecanismo de inovação curricular. Participaram de diversos movimentos de formação continuada e em serviço.

Por meio de uma abordagem qualitativa, procuramos apreender a dinâmica, a complexidade e o desenrolar da trama curricular em seu próprio contexto, sempre a partir dos significados atribuídos por seus atores ao cumprimento da tarefa. A partir de uma pergunta inaugural, quando foi pedido aos professores que relatassem as suas experiências profissionais, criou-se uma narrativa sobre a origem do calendário e do método indutivo intercultural; ressaltaram o seu uso e desenvolvimento na escola, bem como os dilemas e lacunas ao longo de todo esse período. Outro aspecto importante foi colocar os dados numa ordenação temporal, isto é, a narrativa sobre a construção curricular a partir do calendário socioecológico possui uma origem ou fundação, um tempo inicial para a concretização do projeto e, a partir daí, os sucessos e dificuldades em seu desenvolvimento.

Nossa análise teve como foco os impasses vividos pelos docentes e as saídas encontradas na resolução de seus conflitos. Trata-se de uma situação que envolve a relação do professor consigo mesmo, dele com o grupo docente e com as políticas públicas em vigor. Buscamos identificar os elementos que configuram e fornecem apoio às mudanças curriculares, consideradas como rupturas no transcurso das experiências escolares. 
O uso do calendário socioecológico na estruturação do currículo das escolas indígenas:

uma proposta interdisciplinar e intercultural

\section{ANÁLISE DOS DADOS}

O eixo norteador da construção de uma proposta político-educativa para a escola indígena diferenciada é a valorização dos costumes, crenças, valores, formas de aprender e de conviver, invertendo a lógica hegemônica dos conteúdos universais. Vejamos o que nos diz um dos entrevistados sobre os desafios uma educação intercultural:

Já venho trabalhando na escola há 10 anos, e como tem essa ideia de buscar uma escola diferenciada, voltada pra realidade do nosso povo, que isso que tem de mais forte na formação de nossos professores indígenas. Então ela foi proposta pelo próprio povo Xakriabá, que viesse de uma formação que atendesse a demanda daquele povo. Uma concepção totalmente diferente da concepção da educação que pessoal das escolas regulares tem, que o Estado tem (Rede Estadual de Educação de MG). As escolas regulares trabalham conforme 0 Estado orienta, e é ideia nossa era trabalhar conforme a comunidade orienta.

Um dos entrevistados relaciona os impasses entre as proposições feitas pelos gestores da Rede Estadual de Educação e as orientações vindas das lideranças indígenas. Olhando os documentos relativos à grade escolar, percebemos que a cultura adentrava na escola por meio de quatro disciplinas: de "Cultura", de "Artes", de "Práticas Culturais" e do "Uso do Território". Essas disciplinas representavam a possibilidade de articular a tradição e os saberes acadêmicos. Porém, de maneira semelhante às outras disciplinas que compunham a grade curricular, eram "controladas" pelos gestores que queriam que os professores indígenas seguissem os conteúdos e as propostas curriculares das escolas urbanas. Porém aspectos específicos da cultura Xacriabá, presentes nessas disciplinas, ganhavam visibilidade no cotidiano escolar. Como as práticas docentes avançaram?

Segundo um dos entrevistados, o que inicialmente mobilizava os docentes indígenas recém-formados tanto pelo curso de Magistério quanto pela Licenciatura Indígena na UFMG era a negação de uma escola que desconsiderava a cultura Xakriabá. Aquilo que antes não era dito, ou foi se perdendo no tempo, começou a se transformar no contrato daquele grupo de professores. Vejamos o excerto a seguir:

Então o curso de formação do magistério teria que dar conta disso. A gente vinha numa discussão muito séria sobre isso: que as escolas indígenas não vinham fazendo esse papel. Essa educação diferenciada estava como se fosse uma escola regular mesmo. No início, até que os temas principais da cultura eram trabalhados. Com o decorrer dos anos, foram se perdendo, e a gente sentiu muito. A gente vinha sempre nessa discussão. 
Inferimos que, nessa situação, as disciplinas relacionadas à cultura indígena conviviam paralelamente com as disciplinas tradicionais. Porém, estas mantinham seu caráter hegemônico, e, com o tempo, as práticas se direcionavam apenas para esses conteúdos. Segundo o excerto, não se notava diferença com as práticas de uma escola tradicional. Nota-se aqui o enfraquecimento do projeto docente ao longo do tempo, isto é, com o decorrer do tempo iam se perdendo as interações entre os temas de cultura e os conteúdos disciplinares. A frase a gente vinha sempre nessa discussão sugere formas de regressão daqueles docentes diante de um contrato narcísico (KAËS, 2005) que se mostrava frágil naquele momento: a sensação era de um grupo que não saía do lugar. Os docentes começavam bem o trabalho, mas o currículo diferenciado não evoluía. Conforme o excerto anterior, a gente vinha numa discussão muito séria sobre isso, isto é, a educação intercultural constituía o pano de fundo daquele grupo. Mas, ao se tentar colocar em prática, surgia a diferença entre as culturas, e novamente, com o tempo, a cultura indígena se tornava marginalizada frente à cultura científica e escolar, em concordância com o excerto, com o tempo isso ia se perdendo.

Segundo um dos professores, em sua entrevista, algumas perguntas balizavam as dúvidas que perpassavam os docentes: O que fazer para construir essa escola diferenciada? Como a gente vai encarar isso? Que proposta a gente tem para colocar? Essas questões vinham sempre nas reuniões de professores. Percebemos que, naquele momento, a grande dúvida daqueles professores era relacionada a quem garantiria a sustentação de um projeto de escola diferenciada ao longo do tempo.

A crise é uma das faces do negativo. Estamos aqui diante de um relato cujo sentido inovador do trabalho inclui a representação das incertezas e as complexidades da origem de um projeto para uma escola indígena diferenciada. Os excertos mostram a preocupação dos professores com a tarefa básica da escola. Paralelamente, inferimos também o sofrimento e dúvidas que perpassavam cada membro, o sentimento de desunião, a não identificação entre eles, cada um procurando os pontos de apoio e referências profissionais. Perguntamos: Como construir um processo identificatório e representações compartilhadas entre os docentes? Na visão desse professor, a dificuldade de se criar práticas novas, aliada à resistência da Secretaria Estadual de Educação, fazia com que as atividades alternativas propostas fossem apenas ações isoladas em algumas escolas:

Às vezes, trabalha práticas isoladas, de temas que têm significado muito grande para a comunidade. Só que eram atividades isoladas. Uma escola trabalhava, a 
O uso do calendário socioecológico na estruturação do currículo das escolas indígenas:

uma proposta interdisciplinar e intercultural

outra escola no outro ano trabalhava. Ou duas escolas ao mesmo tempo. Não tinha uma continuidade. Então, desde que a gente começou fazer o FIEl em nível superior, essa discussão ela se intensificou mais na $F A E$, e nos encontros de professores ganhou mais força. Só que a discussão ela acontecia lá com os professores; e depois, todo mundo voltava para casa, e ai não encontrava mais. Aí morria.

Encontramos, novamente, as questões relacionadas à sustentação do projeto ao longo do tempo: ter ou não ter continuidade. Pelo excerto, inferimos que os modos de atuação eram discutidos e compreendidos de maneira eficaz na presença dos professores da Faculdade de Educação (UFMG) que, como intermediários, conseguiam aproximar o que estava distanciado, mesmo que momentaneamente. Afastados daquele espaço (todo mundo voltava para casa), o enfrentamento das mesmas questões paralisava o grupo (Aí morria). Segundo o entrevistado, a falta de diálogo (aí não encontrava mais) fazia com que cada um se entrincheirasse. Como saíram desse impasse?

A capacidade dos docentes em projetar o trabalho e as atividades no futuro parece ser um mecanismo importante para iniciar a sustentação o trabalho pedagógico, e, simultaneamente, se engajarem nas ações. Vejamos o excerto a seguir:

Outras demandas no sentido de ofertar uma educação que atendesse a demanda da comunidade, e essa nova demanda ela veio acontecer com os alunos do ensino médio. Então a evasão escolar nesse nível de ensino era muito grande, os jovens chegavam ao ensino médio e ficavam ali um ano, dois, e depois desistiam porque não tinham uma expectativa, um olhar para o futuro. A maioria deles saía para o corte de cana lá fora.

Percebemos que a tarefa, na fase inicial, tem que produzir uma ilusão, cuja intermediação é o contrato narcísico. Dessa forma, não apenas se regularia melhor a evasão dos alunos - principalmente no Ensino Médio - mas também a permanência deles na escola e na aldeia com melhor qualidade. Refletir sobre a dificuldade dos alunos indígenas na educação média direcionou a prática para um trabalho mais integrador, que envolveu também o entorno da escola. Vejamos:

Aí a gente começou, primeiro, a ver qual era a necessidade dos alunos, o que a gente poderia fazer para que esses alunos permanecessem na escola. Começamos primeiro uma investigação sobre isso, e nesse primeiro momento, voltando a experimentar práticas pedagógicas diferenciadas com a professora Lucinha (Lucia Helena Alvarez Leite, da FaE-UFMG), a desenvolver práticas nesse sentido: pensar o ensino médio de forma integrada, não por disciplina. Pensar algo que fosse mais atrativo para os alunos, trabalhar de uma forma diferente, 
e a gente acabou realizando umas experiências nas escolas e a gente viu que dava liga. Tinha uma aceitação boa por parte dos alunos porque a gente evitava ficar dentro da sala de aula, fazia divisões em grupos, foi feito pesquisas pelos próprios alunos, e aí a gente lecionava organizando as turmas em grupo, com conteúdos que a gente via que eram importantes para os alunos e interessante também, além dessa parte mais cultural.

Aí a gente viu que dava liga. Em nossa interpretação, para que as práticas nas escolas indígenas avançassem, tornava-se necessário uma inibição da herança institucional tradicional: não pensar a instituição significa silenciar a debilidade e a dúvida na construção de atividades novas. Se inicialmente o centro da proposta eram os conteúdos universais que a SEE-MG repassava para todos, agora a lógica para se pensar o currículo centrava-se também no aluno, em seus interesses, em suas concepções, além dessa parte mais cultural. A resposta dada pelo entrevistado ao que fazer na fase inicial mostra o que parece ser comum nos momentos originários de construção de projetos inovadores: um momento de experimentação, trabalhar de forma diferente, em que cada docente procura construir um espaço de continuidade e intimidade com o projeto. A presença da professora Lúcia Leite, da UFMG, parece ser importante como ponte nessa ruptura: o fato de ela dominar o saber e qualificar a participação docente, criando espaços de diálogo (discussões e pesquisas), garantia o processo de mediação (vimos que dava liga). Mais do que isso, os docentes acharam um lugar onde pôr os conteúdos (a gente lecionava organizando as turmas em grupo, com conteúdos que a gente via que eram importantes).

Subjacente a essa prática encontramos uma ruptura com a organização por disciplinas, e o trabalho pedagógico organizado por áreas de conhecimento. Segundo os professores, uma prática organizativa para o Ensino Médio que favorecia a aprendizagem dos alunos. Porém continuava como uma prática isolada, tendo sido apenas uma atividade do curso de formação indígena. A partir dos êxitos e falhas dessas atividades, um grupo (alunos indígenas) ficou esperando o outro (docentes da Universidade) na continuidade das atividades inovadoras. E vice-versa. Apesar dos avanços, a mediação foi perturbada porque permaneceu precária a solda no contrato narcísico (KAËS, 2005). Como criar um sentimento de pertença e identificação nesse momento, capaz de promover a capacidade de criação?

A expectativa de se construir um projeto educacional que mobilizasse a comunidade escolar apareceu no momento em que o grupo docente indígena se deparou com uma apresentação do calendário socioecológico como possível estruturador do currículo escolar: 
Os problemas mesmos a gente não tinha conseguido resolver, e já tinha a Profa. Márcia Spyer Resende, a Prof. Lúcia Helena Alvarez Leite, a Ana Gomes, e a gente estava sempre perguntando e propondo para ela que a gente precisava pensar um modelo de ensino para as escolas indígenas. Aí tivemos a felicidade da Márcia já ter contato com essa experiência do calendário, que é o método indutivo intercultural, uma proposta apresentada por Jorge Gasché. Ela fez uma apresentação de como era esse trabalho, como que era organizado, falou sobre essas atividades que partiam mais do cotidiano do povo e explorava isso com os alunos.

Dessa forma, tanto o calendário quanto o método indutivo intercultural chamaram muito a atenção dos professores, uma vez que permitiram ver saídas para a construção de uma escola diferenciada. Nesse momento, tanto a professora da UFMG, Márcia Spyer, quanto o calendário socioecológico são considerados intermediários (KAËS, 2005), pois retiram os membros do grupo da situação de inércia, levando-os a se identificarem com o novo projeto. Ambos promovem a ilusão capaz de fazer com que o docente adira ao trabalho. Temos claro que o uso do calendário é também um intermediário, pois capaz de amalgamar os diversos elementos do conjunto, antes desarticulados:

Os alunos investigavam os conhecimentos dos sábios da comunidade, e exploravam o máximo desses conhecimentos. Essas atividades estavam acontecendo no contexto social das comunidades, e era uma coisa que era do conhecimento dos alunos, era uma coisa que o aluno estava fazendo, que fazem no dia a dia. Então esse saber fazer, que é uma questão que é da cultura, acabou chamando muita atenção por que é basicamente o modelo da educação que a gente quer, que trabalha com a cultura, com o cotidiano do povo, mas que também produz conhecimento nessa linha do saber escolar.

Percebe-se claramente que o calendário articulou os docentes, os alunos, os saberes acadêmicos e a cultura Xakriabá. A possibilidade de incorporar o saber-fazer das práticas cotidianas, a cultura indígena e a fala dos sábios e anciãos terminava por chamar muito a atenção. Esse contato criava um sentimento de coesão no grupo.

Em nossa interpretação, o calendário encontra o seu lugar no espaço grupal, pois, conforme visto no excerto anterior, trabalha com a cultura e, simultaneamente, produz conhecimento na linha do saber escolar. É esse insight que permitiu tirar os docentes indígenas da situação de repetição e impasse que viviam, e foi capaz de criar novas referências identificatórias para a comunidade. Essa reunificação é logo transformada em trabalho e conhecimento, como vemos a seguir: 
Tem um conhecimento escolar lá no fazer a prática que acontece na comunidade. Como você pode explorar isso pedagogicamente? Então começa a aparecer algo diferente, e a Profa. Márcia Spyer, vendo que a gente teve interesse de entender o método indutivo intercultural propôs que a gente assistisse uma palestra do professor Jorge Gasché. A gente teve uma oportunidade de ouvir o professor, ele colocou todo o processo como que é feito os objetivos, enfim, qual a base que é fundamental dentro do método, e a gente ficou bastante interessado. Aí a gente começou também a entender mais daquilo e pensando também já fazer isso nas escolas (grifo nosso).

Estamos diante do contrato narcísico (KAËS, 2005) presente no momento fundacional: reflexões múltiplas em um espelho, indicativo do investimento que cada um faria no projeto de construção de uma escola diferenciada indígena. Notamos, também, ser bastante forte a ideia presente na concepção teórico-conceitual do método indutivo intercultural de que as culturas indígena e científica presentes são igualmente válidas. Vejamos:

Um método que fale de parte das atividades culturais, das brincadeiras de aluno, com atividade que tem importância tanto para a comunidade em si como para os alunos, uma atividade cultural que envolve todo mundo e que os conhecimentos escolares dessas atividades podíamos sentar depois com os alunos e fazer; tentar fazer esse diálogo com conhecimentos do povo aqui com o conhecimento escolar. Como é um método que é entre culturas, sem essas questões de sobreposição de um ser mais valido, qual é o verdadeiro ou não. Interessante é fortalecer a cultura, e fazer também que os alunos aprendessem, que é um dos focos nosso aí que a gente tem desde 2000.

Estamos frente à desconstrução de saberes hegemônicos universais e à valorização de outras variantes culturais (MACEDO, 2014). Se a proposição do uso do calendário continuava sendo, naquele momento, uma experimentação, a utopia que o método carregava consigo cristalizava um caminho que parecia trazer segurança a todos. O primeiro passo se caracterizou como uma atividade investigativa. Vejamos:

Em 2009, o professor Jorge Gasché propõe que deveria ser feito um levantamento da situação da escola: como que a escola é organizada, como que o ensino médio funciona, o número de alunos, como a comunidade vê essa escola. No segundo momento, quase paralelo a esse primeiro, a gente começou a desenvolver algumas práticas pedagógicas diferentes. A gente fez a primeira experiência, gostamos muito dela.

Notamos atividades pedagógicas diferenciadas a partir de reflexões no grupo. Novamente encontramos uma tensão na implantação das questões relacionadas ao 
O uso do calendário socioecológico na estruturação do currículo das escolas indígenas:

uma proposta interdisciplinar e intercultural

calendário: romper com as práticas disciplinares e com a carga horária dos docentes na educação básica:

A escola já vem estruturada no modelo do ensino médio, e nos anos finais, do ensino fundamental que é da escola regular, que é organizada por disciplina. No primeiro momento a gente teve dificuldade de romper com isso, em como trabalhar o calendário de uma forma mais integrada por área, e a gente começou a ter problema com a carga horária dos professores.

O retorno constante a essa estrutura vinda da escola republicana mostra o risco constante de se voltar a uma escola mais tradicional. Por outro lado, percebe-se claramente o papel de líder exercido pelo entrevistado junto aos demais docentes: ele fala de si próprio na relação de investimento no trabalho com o calendário, mas também da delegação que recebeu da comunidade. Mas é uma fala à qual ele próprio adere, introduzindo aos demais docentes no pensar e fazer o projeto. É o entrevistado, pelo investimento e capacidade de articulação, que faz agora o papel de intermediário, capaz de sustentar a continuidade e concretização daquele trabalho:

Como envolvia todos nas atividades, a gente acabava superando essas dificuldades. A gente fez práticas, da mandioca, da produção de farinha; a gente fez todas as etapas das atividades que acontecem na produção de farinha, e aí foi explorado tanto na pesquisa quanto na escrita com os alunos. Fazer junto com pessoal foi muito bacana, e além dos meninos estarem adquirindo conhecimento, buscavam os conhecimentos dos sábios da comunidade que é saber-fazer fazendo na prática.

Nesse caso, fez-se uma investigação prévia que permitiu que os alunos apropriassem de um saber presente nas práticas tradicionais da aldeia. E esses discursos dos sábios foram transformados em saberes escolares, numa perspectiva interdisciplinar. A sua concretização, dentro dos limites institucionais, mostrava o intenso clima de criação:

Também tinham oportunidade de trazer para a escola o que eles viam lá, e discutirem numa linha mais direcionada do conhecimento escolar; aí a gente acabou pegando na área da CSH (Ciências Sociais e Humanas) o que a gente pode trabalhar com a produção de farinha, fazer uma linha da produção de farinha na comunidade depois expandisse pra fora da comunidade. Trabalhar isso junto na área de CSH. Aí entra a Geografia e a História. A Física, no jeito de imprensar para enxugar, para depois torrar. Então tem uma prensa e que pode trabalhar nesse sentido que é a mão de força. Tem o processo químico que é da própria água da mandioca que se acaba se fermentando. E nas outras áreas também pode ser trabalhada a pesquisa, a escrita, e a leitura e a siste- 
matização dessa pesquisa uma estrutura mais de texto, texto escolar, a gente viu que tinha e tem a possibilidade de trabalhar nessa linha, e ainda valorizar o conhecimento do pessoal mais velho.

Sobretudo, percebemos na entrevista as vantagens da utilização do calendário ao longo dos anos na educação básica. Primeiramente, o maior envolvimento dos alunos nas atividades escolares:

Montando o calendário e desenvolvendo práticas diferentes. A gente percebe que, quando a gente escolhe uma atividade que é do gosto dos alunos, que tem essa possibilidade de explorar o conhecimento do pessoal daqui, depois fazer esse diálogo com o conhecimento escolar, ele tem proporcionado um maior prazer do aluno vir para a escola.

Em segundo, a aprendizagem dos alunos melhorou:

E assim na escola a gente percebe o objetivo do Estado para a educação escolar indígena que não é assim, digamos, entre aspas, que não é diferente o que a gente também pensa que é os alunos ler, escrever, interpretar, operar as quatro operações nos anos iniciais do ensino fundamental, só que a gente quer fazer com o aluno também que entenda essa cultura.

Assim, longe de ser uma abordagem romântica, encontramos uma escola situada historicamente, onde o currículo construído reflete um processo tensionado com a tarefa e objetivos da Secretaria Estadual de Educação. Por fim, um dos eixos do calendário é o indicador astronômico, que relaciona aspectos da agricultura e plantio de alimentos com a observação dos céus. Na entrevista encontramos explicitamente as interações e formas de convivência entre os saberes científicos e os conhecimentos indígenas:

A gente trabalhou com a colheita do feijão de corda; desenvolveu mais com os alunos da $5 \underline{a}$ serie e $1 \underline{a}$ ano do ensino médio. No primeiro momento, era fazer entrevista, tinha o pessoal da comunidade mais velho e a gente ia conversar com eles. A colheita ocorre no mês de fevereiro, março, mas para isso a gente tem que esperar a fase da lua boa. Então os meninos vão absorvendo o conhecimento daquelas pessoas que estão falando aí agora os meninos vão produzir textos. É com os alunos do ensino médio, retornamos a casa do entrevistado conversar com ela. Ela falou de lua nova, lua nova, crescente e minguante, a gente foi tentar entender as fases da lua. Fizemos um modelo para observar as fases da lua, incidência luz do sol na lua.

Percebemos as relações trabalhadas entre os saberes tradicionais e os conhecimentos escolares. No exemplo mencionado, a maneira como os saberes se encon- 
tram na redução temática proposta, bem como a explicação dada pelo entrevistado sobre a influência da lua no cultivo e colheita do feijão, e sua relação com os modelos científicos, mostra a criação de um conjunto extremamente satisfatório do ponto de vista explicativo. Tais ações demonstram a seriedade com que os docentes indígenas vêm tratando a prática pedagógica em suas escolas.

\section{CONCLUSÕES}

A pesquisa apresentada nesse trabalho traz um caminho para a construção de um currículo escolar indígena. O trabalho dos professores envolvidos evidenciou as dificuldades de se incorporar a "cultura indígena" na escola. O peso da tradição instituída e de uma concepção hegemônica de cultura mostrou-se muito forte na concretização do projeto. Também possibilitou a nós, professores do FIEI/CVN, perceber os desafios enfrentados ao se colocar em prática uma pedagogia centrada no Calendário Socioecológico. Acreditamos, sobretudo, que o diálogo intercultural nas aulas do Curso de Formação Intercultural para Educadores Indígenas se torna mais relativizado à medida que vivenciamos, nas aldeias, a cultura e as práticas sociais que lá acontecem.

Não temos dúvidas de que o projeto que nos ocupou neste texto é original em sua dimensão curricular e organizacional. Contudo ele surgiu e se desenvolveu no interior do sistema estadual e suas diretrizes para a educação. Conforme mencionamos, a tensão entre a tradição instituída e a mudança instituinte pode ampliar ou reduzir esse espaço intermediário no qual o projeto é formulado, facilitando ou não o seu desenvolvimento. Vimos, também, uma questão que parece fundamental quando olhamos o grupo em espaços institucionais: a atuação que tiveram os gestores da Secretaria Estadual de Educação, na qualidade de líderes, anteriormente ao desenvolvimento dos projetos; ao direcionar os conteúdos para aqueles mais tradicionais das escolas urbanas, as suas atuações se afastavam do que poderia ser uma intermediação (KAËS, 2005). Nesse contexto, o desafio de se incorporar a cultura indígena é reduzido a uma dimensão técnica e instrumental.

O referencial psicanalítico permitiu responder às nossas indagações sobre as mediações entre o sujeito singular e a realidade histórica. Tal embasamento permitiu-nos compreender o investimento dos professores indígenas recortados pela história cotidiana e unir a intersubjetividade, de onde o sujeito pode advir. Nesse aspecto, a entrevista do professor indígena que utilizamos cumpriu o papel de contar uma história da construção curricular de sua escola. Tal relato mostrou os 
conflitos identificatórios que nela ocorreram, enquadrados pelo tempo histórico. Os sentimentos de hostilidade, de distância, de insegurança e de impotência, que surgem frequentemente nos grupos profissionais diante da instauração de experiências inovadoras, foram claramente percebidos no momento inicial da proposta. Assim, vários intermediários foram levantados ao longo da entrevista: o próprio entrevistado junto com as professoras da UFMG, Lucinha Alvarez Leite e Márcia Spyer Resende, pela capacidade de sustentar a ilusão inicial contida na proposta; o calendário, como elemento mediador entre o grupo docente, o contexto institucional e da dinâmica da relação com o meio social externo; e as identificações em espelho que foram surgindo- contrato narcísico- capaz de negar, em diversos momentos, as debilidades e angústias de cada um no trato com as experiências inovadoras-pacto denegativo.

O grande salto inicial foi dado pela percepção do calendário como intermediário: ao perceberem a força que o calendário poderia ter na construção de atividades escolares envolvendo os conhecimentos tradicionais indígenas e o conhecimento científico, transformaram a desilusão inicial em investimento no projeto, criando um sentimento de continuidade precisamente quando se enfrentava um momento de separação. Diante de questões que cada um se fazia - O que essa proposta realmente significa? Qual a nossa capacidade de dar conta dele? - ficava o indício de que havia ali uma excelente ideia, um projeto capaz de seduzir toda a comunidade indígena. Em concordância com Kaës (2005, p. 185), são essas formações e pactos que impedem a compreensão de que os ideais comuns gerem uma inquietante estranheza em nós mesmos: o que se torna estrangeiro a nós mesmos é o papel que temos na sustentação desses ideais e que nós não sabemos. Tanto na manutenção dos antigos vínculos quanto na invenção de novas vinculações, somos confrontados com esse inacabamento (FREIRE, 1982), pois ele se relaciona com a possibilidade de questionamentos dos valores interiorizados pelos sujeitos, grupos e instituições. Sua função organizadora produz, no conjunto, a construção e a orientação de suas condutas, suas posições, os novos lugares, a relações com o outro, sempre perpassado por modificações no exterior. Isso significa que o próprio fato de participar do projeto adquire a função de experiência transicional, permitindo garantir a sustentação do projeto e, simultaneamente, parte da ilusão inicial, pois cria novos contratos com a instituição educativa.

Em segundo, um aspecto que tem chamado muita a atenção dos futuros docentes em sala de aula é a não dissociação método e conteúdo: o aprender é inseparável do como aprender. Talvez sejam essas interações entre cultivo, vivência, 
trabalho e saber que devemos aprender com os povos indígenas. Sem dúvida alguma, os conteúdos do Curso de Formação Intercultural para os Educadores Indígenas da Universidade Federal de Minas Gerais (FIEI/UFMG) buscam uma ressonância com os projetos pedagógicos demandados pela comunidade escolar. A importância dessa aproximação, em conjunto com a necessidade dos professores e bolsistas da UFMG conhecerem o território indígena, levou o curso a ter momentos específicos de formação: o Módulo, que é um tempo de interação entre professores e alunos que ocorre na Universidade; o Intermódulo, no qual a interação direta ocorre nas aldeias.

Por fim, no que diz respeito aos processos de formação no FIEI, nos pareceu que alguns pontos são importantes. Primeiramente, a ação formadora pode contemplar dois caminhos: um diz respeito ao fortalecimento do sujeito (aprendizagem da dúvida, do questionamento e do saber obtido - a alegria da certeza e a falta: saber e certeza só coincidem no modelo) e outro voltado à adaptação do cotidiano. Isso implica uma parte de trabalho e outra de ilusão (capacidade de saber que vai se apropriar de seu trabalho).

\section{REFERÊNCIAS}

BRASIL. Ministério da Educação. Conselho Federal de Educação. Parecer 13/2012. Diretrizes Curriculares Nacionais para a Educação Escolar Indígena. Diário Oficial da União, Brasília, Seção 1, página 18, 2012.

CUNHA, M. C. Políticas culturais e povos indígenas: uma introdução. In: CUNHA, M. C.; CESARINO, P. N. (Org.). Políticas culturais e povos indígenas. 1. ed. São Paulo: Cultura Acadêmica, 2014. p. 9-21.

D’ANGELIS, W.R. Contra a ditadura da escola. In: GRUPIONI, L. D. B (Org.). Formação de professores indígenas: representado trajetórias. Brasília: SECADI, 2006.

EL-HANI, C. N; SEPÚLVEDA, C. Referenciais teóricos e subsídios metodológicos para a pesquisa sobre as relações entre educação científica e cultura. In: SANTOS; F. M. T; GRECA, I. M. A pesquisa em ensino de ciências no Brasil e suas metodologias. Ijuí, RS: Ed. Unijuí, 2006.

FREIRE, P. Pedagogia do oprimido. São Paulo: Paz e Terra, 1982.

GASCHÉ, J. ¿Qué son 'saberes' o 'conocimientos' indígenas, y qué hay que entender por 'diálogo'? In: PÉREZ, C.; ECHEVERRI, J. A. (Ed.). Memorias 1er Encuentro Amazónico de Experiencias de Diálogo de Saberes. Leticia, 10 al 12 de noviembre de 2008. Leticia: Editorial Universidad Nacional de Colombia, 2010.

GOMES, A. M. R.; MIRANDA, S. A. A formação de professores indígenas na UFMG e os dilemas das culturas Xakriabá e Pataxó. In: CUNHA, M. C.; CESARINO, P. N. (Org.). Políticas culturais e povos indígenas. São Paulo: Cultura Acadêmica, 2014. p. 455-83. 
GUTIERREZ, A. L. G. Notas conceituais sobre a relação entre justiça curricular e currículo intercultural. In: LOPES, A. C.; ALBA, A. (Org.). Diálogos curriculares entre Brasil e México. Rio de Janeiro: EdUERJ, 2014.

KAËS, R. Os espaços psíquicos comuns e partilhados: transmissão e negatividade. São Paulo: Casa do Psicólogo, 2005.

MACEDO, E. Currículo, cultura e diferença. In: LOPES, A. C.; ALBA, A. (Org.). Diálogos curriculares entre Brasil e México. Rio de Janeiro: EdUERJ, 2014.

\section{Sobre os autores:}

Cleunice Barros de Andrade Nunes: Docente da Escola Estadual Indígena Kuhinãn, Aldeia Rancharia, Território Indígena Xakriabá, Minas Gerais. Licenciatura em Formação Intercultural para Educadores Indígenas (Área CVN) / UFMG. E-mail: cleusa76@yahoo.com.br

Juarez Melgaço Valadares: Docente da Faculdade de Educação e do Mestrado Profissional Educação e Docência/FaE/UFMG. Licenciatura em Física pela UFMG. Mestrado em Ensino de Ciências e Doutorado em Educação pela USP. Pós-Doutorado PPGEd/UFRN. E-mail: juarezm@ufmg.br

Célio da Silveira Júnior: Docente da Faculdade de Educação da UFMG. Licenciatura em Química e Mestrado e Doutorado em Educação pela UFMG.E-mail: celio@fae.ufmg.br

\section{Recebido em agosto de 2016.}

Aprovado para publicação em março de 2017. 